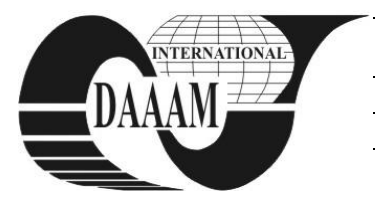

\title{
THE APPLICATION OF NETWORK TECHNOLOGIES TO CONSTRUCTING GROUP CONTROLLED SYSTEMS WITH MACHINE VISION FOR MOBILE ROBOTS
}

\author{
PRYANICHNIKOV, V[alentin] E. \& ANDREEV, V[ictor] P[avlovich]
}

\begin{abstract}
Based on the analysis of information streams in information-measuring control systems (IMCS) mobile robots (MR) with supervisory control, an integrated approach of constructing information-measuring systems with machine vision technology (MVT) was put forward and their functional formulation was identified, which all represents the base of the idea of constructing group controlled MR. The scheme, displaying dual movement structure of information streams in distributed IMCS MR with supervisory control, was suggested. MVT MR was suggested to be regarded as a local area network (LAN) with mobile components.
\end{abstract}

Keywords: machine vision technology, information-measuring control systems, local area network, supervisory control

\section{INTRODUCTION}

Creators of mobile robots have recently come to the comprehension of what modern technological and scientific achievements, being in the limits of suitable cost of such mobile robots, in most cases don't allow to create completely automatic systems. So, that the main attention is concentrated on supervisory control of mobile robots. According to work [1], the result of full uncertainty and changeability of the external environment the software control is only suited as a low level of supervisory control but the leading way of controlling has become, first of all, remote control, which have connection with technical vision and other sensory systems of robots. A distinguished feature of such systems (with supervisory control) is: a) presence in the information-measuring control systems (IMCS) of mobile robots two controlling loops - internal and external divided by communication area, besides both controlling loops have the system of technical vision installed on the mobile part of IMCS; b) the external controlling circuit is guided by a person.

\section{ANALYSIS OF INFORMATION FLOW IN IMCS OF MOBILE ROBOTS}

The scheme of information torrents in IMCS of mobile robots with supervisory control is the following. A mobile robot as any complicated controlling system, is consisted of subsystems analyzing the state of external environment and state of the controlling system itself, output of a signal of return connection and a signal of guidance. Evaluating external environment and the controlling system itself is realized with the informationmeasurable system - a number of drivers and software means ensuring collect, conservation and exploration of all incoming data. The system is a part of onboard IMCS and include different remote sensors (ultrasonic detectors, TV-cameras, thermals, scanning devises/gamma locators) etc.

In the system of supervisory control the analysis of data and determining a goal of control is brought to completion by a person receiving about $80 \%$ of information through the sight. Consequently the information about the world around should be given to the person in accustomed way namely in the form of bitmap. That's why it's necessary to use a TV-camera (or several cameras) as the main remote sensor. In visible range the function is completed by standard matrix TVcamera and by thermals in IR one. The human factor in IMCS of a mobile robot with supervisory control turn the system of the technical vision into the dominant information channel.

The signals incoming from different detectors are exposed to various noises and distortion. It can be flotation noise, optical deformation (for example, assorted aberration) distortion brought about by not ideal characteristics of sensors themselves (for example, the geometric noise of multielement IR detectors). So according to Morre' paradigm, the system should possess a module of preprocessing of signals that is aimed at filtering these noises and correcting the deformations. As a rule the objective of the module is to transform analog signals into digital form. A striking feature of mobile robots consists in dynamic character of incoming information, consequently the module has to complete its function in real time scale. A common computer don't cope with such an enormous data flow so as a rule processing of signals is fulfilled with the help of particularized processors.

Video signals from TV-cameras and ones from other remote sensors should be turned into a loop of structured data which is necessary to prepare for transiting within communication channels (communication environment). Under a data loop it's accepted to understand a structured uninterrupted data flow which goes from all the onboard sensors of MR and commands of control which are set in certain sequence by determined rules.

Wired spread-spectrum digital channels of transmitting data (for example common bus) can be used for transferring data within inner communication channels of MR (for example to inner interface). Then purified from various noises digital images and other data get straightly into the memory block where analysis of data of inner interface is completed. 
The internal interface includes transfiguring incoming signals to standard kind, analyzing the data, forming particular purpose of controlling and proper commands or plan of controlling and transmitting them in the formation command module of MR for carrying out creating the most internal control circuit. For the functions demand a calculator but its calculating resources can't be enormous, the reason for that are considerable expenses on proper IMCS and great energetic expenses. But in several cases when MR is able to carry on board a petrol or diesel electric generator (for example, MR for emergency group installing of powerful calculator is possible.

The most efficient algorithms for signal preprocessing is adaptive algorithms that use the result of analysis of information on the ever-changing external environment to adjust its parameters. The pre-signal processing parameters may also be affected by the purpose of control, for example, it is possible to raise the high frequencies (contrast) on a fragment of the image, which requires special attention. Commands to change the parameters of preprocessing comes from the internal interface of the module through the formation of control commands, creating a feedback loop.

A module of forming commands of control include the transformation of the solutions received as a result of the internal interface, the command system determined by specificity of the module of forming of control signals. Modern computers such as Notebook or Netbook is often used as an on-board calculator, bus outputs are USB, but no longer have access to the standard RS-232. At the same time, in most microprocessor-based modules, produced industrially, the control signals are received by tires, working in a standard RS-232, RS-485 or I2C. In fact, the module of forming of control commands is an interface transformer that allows you to use a microprocessor modules of different manufacturers.

A signal formation signal control module is a transformer of control commands in electric signals which come to executive mechanisms through proper amplifiers. Usually this is a microprocessor having its system of microcommands and electronic keys for switching on and off the gears of executive mechanisms. The feedback loop serves for controlling executive mechanisms of remote sensors IMCS. For example thus control of the turn-incline mechanism and function of the optical scaling cameras (PTZ) are carried out.

A number of problems related to communication environment appears when transmitting loop of data by radio channels on remote interface. Use of analog radio channels comes to the problem of bandwidth which in the case should be enough for transmitting standard TVsignals from many cameras; it's difficult and expensive to be ensured. Besides analog radio channels have low interference immunity. But the digital method of transmitting data by radio channels is a way to solve the problem.

Performing a purpose of control and compiling a plan to achieve the purpose, including a number of commands for executive mechanisms, are based on analyzed data.
Depending on complexity of current tasks data analysis and performing purpose of control can be made not only with the remote interface but with the inner one.

It's necessary to take into consideration that setting up a radio channel with $100 \%$ reliability is practically impossible, that's why the internal interface is responsible for fulfilling a certain ultimate number of navigational tasks in automatic regime, for example, return into the zone of stable radio reception if radio control is lost.

The remote interface performs transformation incoming signals to standard kind, analyzing the data, forming particular purpose of controlling and proper commands or a control software and transmitting them in the formation command module of MR. Depending on the type of control (remote or supervisory) analysis of incoming data and the formation of objective control are carried out by a human operator or a machine, plus a human operator. In both cases, the incoming information should be displayed on the monitors control panel in the form most suitable for human perception, and taking into account the dynamic nature of this information. For technical vision systems, all incoming video streams should be converted into raster images on the monitors. Also, mnemonic images that reflect the testimony of other sensors installed on MR: evidence of ultrasonic sensors, odometers, state of the system power supply $\mathrm{MP}$, the current state of radio channel, etc, all of that should be formed on the monitors.

As a final decision on the control objectives is produced by a human operator, control panel (OP), which is part of the remote interface must contain elements of control that meet the requirements of ergonomics: toggle switches, joysticks, etc. Implementing all of the mentioned functions lays on the computer IP, performance requirements of which are determined by the number of video streams that need to be decoded into a sequence of bitmap images generated with the standard frame rate $(25 \mathrm{f} / \mathrm{s}$ for PAL or $30 \mathrm{f} / \mathrm{s}$ for NTFS). In the case of supervisory control computer gets to the function of the data analysis and developing control objectives within the commands, coming from a human operator.

\section{THE FUNCTIONS AND COMPONENTS OF A VISION SYSTEM}

Analysis of data flows determines the right mix of equipment. Fig. 1 shows an embodiment of the construction of MVT MR with supervisory control, which is consistent with the two-loop structure of information flows. On board of MR video-sensors are installed (cameras, IR-thermal images, scanners, etc.), and this set of video signals must be sent via wireless systems in the control console (OP), then to display them on the monitors. Analysis of incoming images is performed by the operator MR, which, in its turn, controls by the radio channel executive mechanisms of the complex in the case of a system with a remote control or form the enlarged set of instructions (software) in supervisory control. These functions of MVT imply the presence following components: 


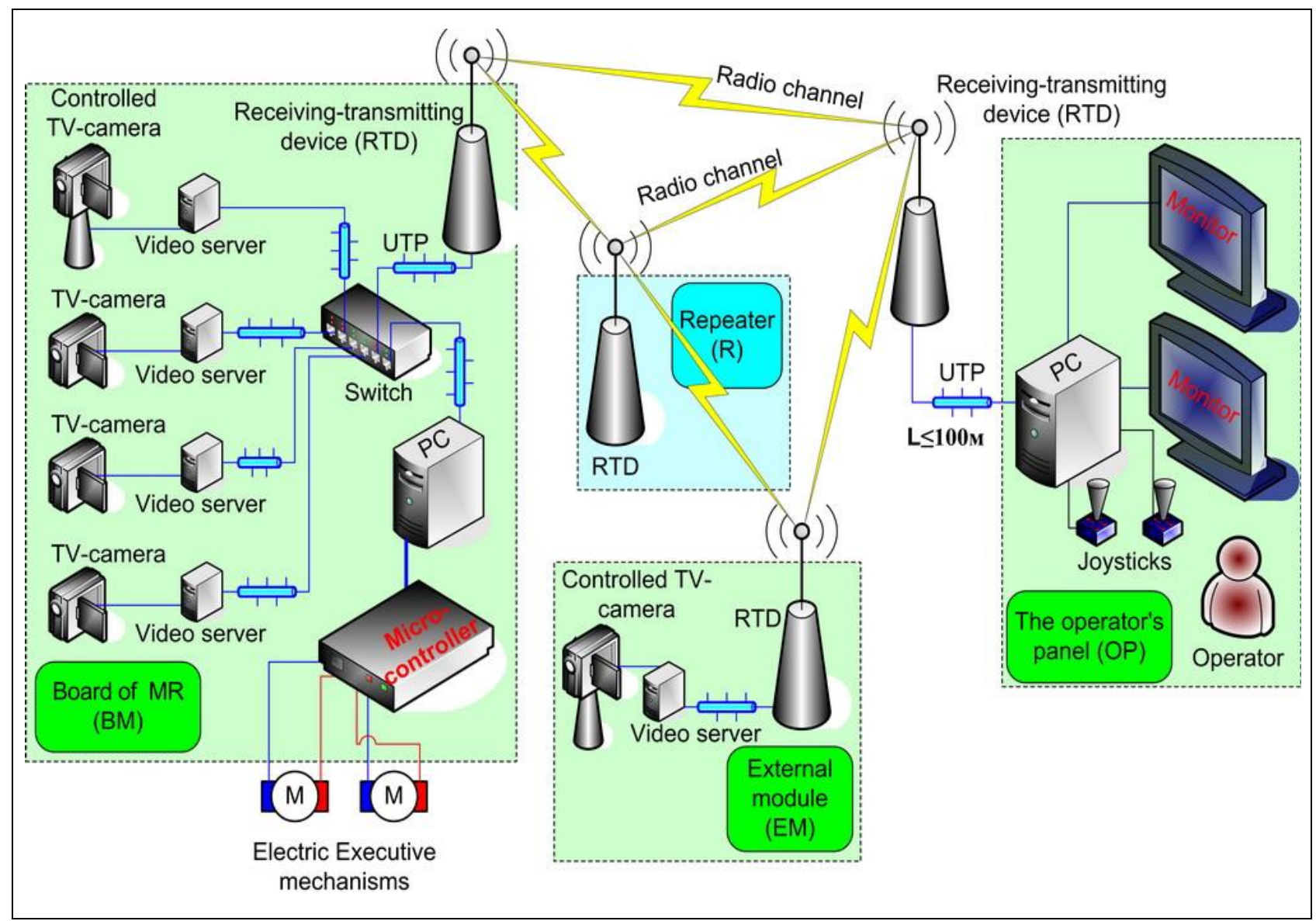

Fig. 1. Embodiment of the construction of MVT MR with supervisory control

1 Optical radiation sensor system with appropriate optics and electronic form video (TV-camera, IR-thermal scanner, a scanning probe gamma radiation, etc.).

2. System of collecting and filtering video signal (analog or digital) for the correction of distortion and transformation of images into a different form of representation with the help of special processor for preprocessing video and/or video server, that converts analog video into digital form, compression, and reduction to standard Ethernet, and etc.

3. The system of forming a radio channel (two-way radio - RTD) for communication between the on-board module (BM) and a remote control. This channel of communication is used for transmission of video (and / or data from other sensors) to mobile MVT, and for the transmission on board of MR actuator control commands, including turn-incline mechanism of cameras (PTZ).

4. Repeater $(\mathrm{R})$ is designed primarily to obtain a stable channel at large distances and solve the problem of direct radio visibility.

5. The control unit (operator panel - OP), includes the system of a channel formation and the system of decoding loop data, the operator interface (control console), a system of converting video into a bitmap display of video information control system - it can be a particularized computer or a standard PC.
6. Systems of autonomous power of electronic components and drives of executive mechanisms of mobile modules.

7. Calculating device on the mobile robot with supervisory control, performing data analysis and developing control objectives (internal interface).

8. External Modules (EM) with installed on them controlled cameras ("satellites") are located in the immediate proximity of the area of the work of MR and allow the operator to observe the work of its executive mechanisms.

\section{SYSTEM OF TECHNICAL VIEW AS THE LOCAL COMPUTER NETWORK WITH MOBILE NODES}

Let's stop on some aspects of designing of MVT for mobile robots. We consider thus that ensuring completeness of information about working spot and its reliability are the necessary condition of minimization of mistakes at formation of the purposes of control.

Completeness of data is provided by possibility of the full review of the action place, and reliability of data is defined both technical characteristics of sensors, and ways of extraction and submission of information. It should be noted that technical characteristics of sensors also influence completeness of data; as an example resolution of sensors. 
The review of the action place on MR is carried out by system of technical vision with sensors of optical radiation. Function of the full review can be provided:

a) a TVcamera supplied with the rotary and inclined mechanism PTZ;

b) several TV-cameras fixed on board MR, and on external modules;

c) a special TV-camera with system of the circular review [4].

With reference to MR with supervisor control, the most effective is combination of options a) and b), i.e. option with the operated multiple MVT using TVcameras with the rotary and inclined mechanism and possibility of optical scaling (PTZ) is represented. Use of such EM modules with the TV-cameras fixed on an operated rotary and inclined platform, increases control efficiency of MR. In the organization of works on elimination of consequences of the Chernobyl accident need to observe from outside behind actions of remotely operated robotics complexes was revealed. Portable modules should be independent, therefore, should have the relevant system of power supply and an element of formation of a radio channel for communication with an operator console. Such "satellites" can take place on the simplified mobile chassis (on the robot-observer).

Using MVT with many TV-cameras there is a transfer problem on a radio channel of multistream video as even for one TV-camera at analog-digital transformation of video signal the digital stream can take up to $165 \mathrm{Mbps}$. One of traditional decisions is use of a broadband analog radio channel. However, it is an expensive way as it demands installation on all modules of expensive high-frequency multichannel equipment. Other way is prompted by modern development from area of systems of the security alarm system. Application of IP TV cameras allows to solve a problem of multistream video with hardware compression of images by cheaper and reliable way. In this case there is a transition from analog to digital equipment that allows to use the most advanced Ethernet-technologies methods. Then it is possible to offer a common decision: all elements of digital processing of signals in distributed IMCS of the mobile robot, including control panel elements, should be united in the local computer network (LAN). Then the task is reduced to creation of a LAN with mobile nodes as the digital TV-cameras placed on $\mathrm{BM}$ and VMT, a repeater both an airborne computer on the one hand and the calculator on an operator console on the other hand act. Such distributed IMCS possesses the following properties.

Reconfiguration - possibility of easy to increasing or change any resources of system: TV-cameras, calculators, radio channels, other sensors, and also other IP-systems.

Distribution - possibility to distribute computing resources between modules.

The multi-user mode - possibility to receive other information at the same time on several operator consoles, including on the panels connected to the system through Internet, and controllable at the same time from different OP. Control through the Internet - possibility to analyze work of $\mathrm{MR}$ and to operate its executive mechanisms at any distances. Possibility of digital processing of signals - use of special processors and universal computers that allows to improve constantly pure algorithmic way of processing of signals and control programs.

High quality of images - possibility of use of TV cameras of high resolution with high quality of a color rendition.

Functionality - on the digital channel it is possible to transfer video signal, a sound, control signals as to MVT (for example, rotary and inclined platforms), and the MR executive mechanisms.

Association of MR modules in a LAN through a radio channel - Wi-Fi or Wi-Max standard use, etc.

High noise immunity - unlike analog systems digital data links possess a bigger noise stability.

Security - possibility of usage of methods of protection of information from unauthorized access (for example, VPN channels and/or enciphering, etc.).

Video multistream - ability to transmit video signals simultaneously from several TV- cameras without appreciable decrease in quality of images that is reached at the expense of use of highly effective algorithms of compression of sequence of frames.

It would seem that for MVT it is enough to use IP TV-cameras with the built-in possibility of compression of images and data transmission on Wi-Fi. However it isn't so. The main feature of use of mobile robots is their work in extreme conditions, especially it touches the Ministry of Emergency Situations. In this case the TVcameras installed on MR, should be street and antivandal execution, and to be efficient in a big range of ambient temperatures. Such IP TV cameras are very expensive also their damage, for example, at analysis of blockages, can lead to expensive repair. Therefore on BM and EM it is necessary to put rather cheap analog TV-cameras, and preliminary processing of video signal (transformation to a digital form, a filtration of hindrances, compression, reduction to the Ethernet standard, etc.) to make by means of an airborne computer or the special device called by the video server. This device is situated in the special case which is fixed onboard MR in the protected place.

Due to use of operation of compression of video there is a question connected with possibility of distortion of images as technologies of compression of video reduce the size of a video stream at the expense of rejection of a part of information that leads to decrease in quality of images after its transformation back in a raster form. Let's consider applicability of the algorithms of compression developed so far to a task connected with creation of MVT for mobile robots.

Methods of compression are divided into two big groups [5]: methods of compression of separate images 
and methods of compression of frame sequence. The algorithms of compression relating to the first group of methods, process each frame of personnel sequence as the separate image. Algorithms of the second group use strong correlation between the next frames in personnel sequence, i.e. consider that each following frame, as a rule, differs from the previous a little. Then it is possible to use the first frame as basic (without processing), and the following frames to form from basic and those changes on the image which occurred in time between these frames. It is in addition possible to carry out compression of the most basic frame by algorithms from the first group of methods. The video stream which contains less information in comparison with that option when the video stream is formed of sequence of full frames, let even the compressed as a result turns out.

There are two main categories of compression: compression without loss and compression with losses. Such formats of compression which allow to restore completely the initial image, for example, the GIF format (Graphics Interchange Format) belong to the first category. Technical possibilities of realization of these methods don't allow to use them for compression of video streams. Such methods at which after decoding it is not possible to restore precisely the initial image belong to the second category, i.e. there is a loss of a part of information. At the same time methods of this category allow to provide high extent of compression. Algorithms of compression of the image use, as a rule, a conveyor principle of processing of images therefore at MVT design for mobile devices it is necessary to consider a delay of coding inherent in this principle - time for coding, transfer and video stream decoding is required. Such delay is shown that a various type of movement of objects on the screen of the monitor will be displayed with some delay, but any distortions in dynamics of movements won't be observed. For MR this parameter appears the extremely important, especially when TVcameras with PTZ function are used.Therefore, it is necessary to provide possibility of dynamic control in parameters of compression for finding of an optimum ratio quality image / extent of compression.

Let's consider some formats of compression [6] from the point of view of their use for MR with supervision control.

Today there are two base standards of compression: JPEG (Joint Picture Expert Group) and MPEG (Moving Picture Expert Group). The JPEG standard (ISO/IEC 10918) is used now most widely. The compression principle is put in its basis at the expense of removal from the image of surplus information. The algorithm of compression of JPEG allows to establish at will extent of compression from $1 \%$ to $99 \%$. The extent of compression is higher, subjects of smaller volume the resultant file turns out, but restored image will differ from the initial. Distortions are shown in the form of "blochnost", i.e. on the restored image there are appreciable borders between zones of homogeneous areas (blocks of identical brightness) at smooth change of brightness on the initial image.
For compression of sequence of frames the version of this format - MJPEG (Motion JPEG) is used. This format represents resultant video in the form of sequence of the frames compressed in the JPEG format. Its advantages consist in convenience and simplicity of a choice of a compromise between quality and extent of compression. This format differs high reliability as loss of separate frames from a video stream by transfer on communication channels, doesn't influence other frames.

Formats of MPEG group are intended for compression of personnel sequence and use for compression as redundancy of the image within one frame (similar to the JPEG formats), and correlation communications between the next frames. The main accent was made not on quality of the image, and on the maximum extent of compression.

Today the most perfect format from MPEG group is the AVC/H.264 MPEG-4 Part 10 format or simply the H.264 format. This format possesses big flexibility in relation to a compromise choice between speed of a video stream and a compression delay. In some cases this format of compression allows to receive the decoded images close on quality to the M-JPEG format as for compression more difficult mathematical apparatus, than at his predecessors is used.

What of formats of compression should be used when developing the operated multiunit MVT intended for use in MR? The main for a choice are the following factors.

Frequency of updating of frames. At IMCS of the mobile robot with supervisory control there is a person therefore properties of sight of the person and define this choice. Human sight is very sensitive to frequency of flashing, i.e. to frequency of change of frames. In the film industry for increase of frequency of change of frames in film projection devices use an obtyurator interrupting a projection of the image of each frame on the screen several times (usually 2-3 times), increasing thereby personnel frequency of a projection. In television to these purposes apply interlaced scanning development which increases frequency of frames in 2 times (at the expense of decrease in permission in each semi-frame): for video signal in the PAL (NTFS) standard from 25 (30) frames per second to 50 (60) semi-frames in second. Therefore application of formats of the compression focused on low-personnel TV-cameras, not expediently. As it is paradoxical, but application of low-personnel TV-cameras in MVT for MR can not lead to decrease in a video stream when using formats of compression of MPEG group. It is caused by that in case of dynamic scenes, the more time between two basic frames, the can collect changes on the image, and, therefore, bigger volume of information will be necessary to transfer in a video stream. Besides, quality of the image as accuracy of extrapolation considerably will decrease.

Quality of the image. In MVT for MR changing demands are made to quality of the image. Quality in this case is understood as the size of a raster of the digital image. If MVT is used for robot traffic control, it is possible to reduce quality - to apply a CIF format standard: $352 \times 288$ points of a discrete raster or even 
QCIF: $176 \times 144$ points; here high frequency of change of frames as owing to movement MR the image in frames quickly changes appears more important. For this case it is inexpedient to use the formats, using compression of personnel sequence.

If by means of MR difficult works are performed, for example, analysis of blockages under which there can be people, but thus speeds of robot movement and its executive mechanisms aren't high, it is necessary to be guided by a format providing at standard frequency the best quality.

Capacity of a network. At a large number of simultaneously working TV-cameras the total video stream, which is limited by the capacity of a network, is possible to transfer only at the expense of essential compression considerably increases. There is a contradiction between the quality requirement and receiving essential compression of video streams. The decision consists in a comprehensive approach:

- to use the codecs calculated on realization at once of several formats of compression;

- to provide for each TV-camera (with remote control) the parameters of the codecs which are carrying out compression;

- to provide the operator with possibility far off to switch codecs to the necessary format of compression, for example, increasing quality of coding/decoding of the image for one TV-cameras and reducing this parameter for others. Quality control needs to be organized automatically at the expense of the analysis of the total video stream coming to an operator console, for providing its preset value.

The delay of video signal is time between the moment when the event really occurred, and the moment when this event was displayed. The formats of compression using a basic frame, bring the greatest delay. Though the person by means of training is capable to consider delays in certain limits but where high precision of performance of actions is required, the delay should be excluded.

Reliability. This parameter is especially critical for MVT using a radio channel for transfer of video streams. Here probably short-term loss of communication (often it happens when using $\mathrm{Wi}-\mathrm{Fi}$ ) that leads to admissions in a video stream and, therefore, to loss of basic frames in case of use of formats of compression of MPEG group. As it was noted, the M-JPEG format is steady against such artifacts in the sense that it doesn't lead to distortions in the decoded image. Infrequent and shortterm interruptions of video flows operator only irritate, but it is capable to perform work in such cases. At the same time such interruptions affect work of the majority of decoders (videoplayers) which simply stop the work. It is corrected algorithmically by introduction in the decoder with some logic rules.

Video stream decoding. When using MVT in proportion to number of $\mathrm{TV}$-cameras, requirements to the computing resources, which are carrying out decoding of video streams and their display on screens of monitors in the form of raster images increase. Here it is necessary to consider also that circumstance that the algorithm of unpacking of the video received in a format of compression of H.264, is more difficult than algorithm of unpacking of the video stream received in M-JPEG format.

Influence of external factors. External factors, for example rain, snow, wind, illumination changes, influence dynamics of a scene - all these factors cause changes on the image in personnel sequence. When using formats of compression of MPEG group all these weather phenomena will lead to video stream growth. If to use the M-JPEG format, the video stream won't depend on these factors.

Due to the development of computer facilities there was a possibility to carry out preprocessing of images by means of the small-sized specialized processors having low power consumption and high efficiency. Transformation of analog video signal to a digital form, its compression and transformation to the Ethernet standard is more convenient by means of video servers.

\section{THE FORMATION OF DATA TRAIL AND RADIO CHANNEL ON THE BASE OF IEEE 802.11 STANDARDS}

It is switch that converts data stream to data trail in MVT which we developed. All network devices (all video server outputs, on-board computer, formation module of radio channel, other information sources different sensors with network interface) are connected to the commuter through standard Ethernet interface. Switch is a specialized digital device which allows to send packages between some segments of local area network and which can control traffic on the base of the link-layer protocol of the OSI model (level 2). Formed data trail comes to internal interface or to the module that forms radio signal. In order to merge network nodes through radio channel one uses wireless network which is organized due to WAP - Wireless Access Point. As a rule, WAP also functions as a router. Thus, it is often called wireless router.

At the access point the RISC-CPU executes an algorithm which represents its 3 modes: AP mode, repeater, WDS mode. In the AP mode an access point connects network device with the current net through radio signal. In the repeater mode an access point receives weak signal from another access point, increases it and transmits it to the necessary destination at the same frequency. In the WDS mode an access point integrates outlying segments of the net into one. Nowadays, Wi-Fi (Wireless Fidelity) connection is the most popular.

Wi-Fi devices have limited action radius. Thus, it's necessary to follow some ways in order to increase the action radius. The easiest way is to increase WAP capacity (receiver-transmitter) that sometimes is not possible because of difficult registration process and obtaining private permission from SCRF -State Commission on Radio Frequencies. The second way is to 
use narrow directional antennas. As a rule, it may be difficult to realize within mobile systems. The third way is to create radio signals' repeaters at the same WAP. In this case radio signals between repeaters and the control console are organized due to narrow antennas. Thereby they create strong long-rang secured radio channel and the repeater, which is set near to mobile robots, creates radio channel with on board module due to omnidirectional antennas.

It's also better to use the repeater as a way to increase the reliability of radio communication. As a rule, mobile robot acts in a limited area, but its shunting must not be limited by anything. Thus, one should set functionally less mobile repeater in the robot's coverage. In this case WAP of these devices will be located in a short distance from each other and it will let increase the stability of radio communication. We provide them with omnidirectional antennas. At the same time immobile repeater with immobile software forms more stable radio communication (in the compare with the system mobile robot-stationary console) through the using of narrow antennas. It increases the reliability of radio channel and decreases the chance of unauthorized data access.

It's also necessary to take it into consideration that repeater can be functionally connected with remote vision system module through special WAP settings. Both repeaters and remote modules are better to be installed on mobile controlled chassis which transfer technological mobile robot to its coverage, to the zone of high risk.

The problem of mobile robot's functioning in urban districts, when buildings and other obstacles prevent radio signal from farther transferring, can be solved in the same way. In this case, one can use few repeaters. Moreover, when the access point, (with an antennas) which is charged according to PoE standard (on free twisted pairs of cables of 5e category), may be taken out from the console to the distance of $100 \mathrm{~m}$, if they are combined through UTP (or FTP) cable. It makes possible to control mobile robot's functioning even in cellars or from guardrails. Removal antennas is impossible to connected with a receiver-transmitter through highfrequency long cables, because of strong attenuation in cables of this type.

It is constructively unreasonable to set omnidirectional antennas with high amplification factor on board of mobile robots. Such aerial may be easily damaged because of its big sizes. Moreover, powerful aerial will capture signals from distant outlier sources of radio sources. Due to it the selection of the necessary signal will be tangled. Thus, there must be set antennas with circular pattern diagrams on mobile robot's board. Their amplification factor and WAPs' power will provide safe radio connection in MR's coverage. The size of such zone can be distantly controlled from the console. It's also possible change radio power settings of corresponding WAP.

So, the distance of strong radio connection shouldn't be increased through higher power of receiving and transmitting devices or using antennas with bigger

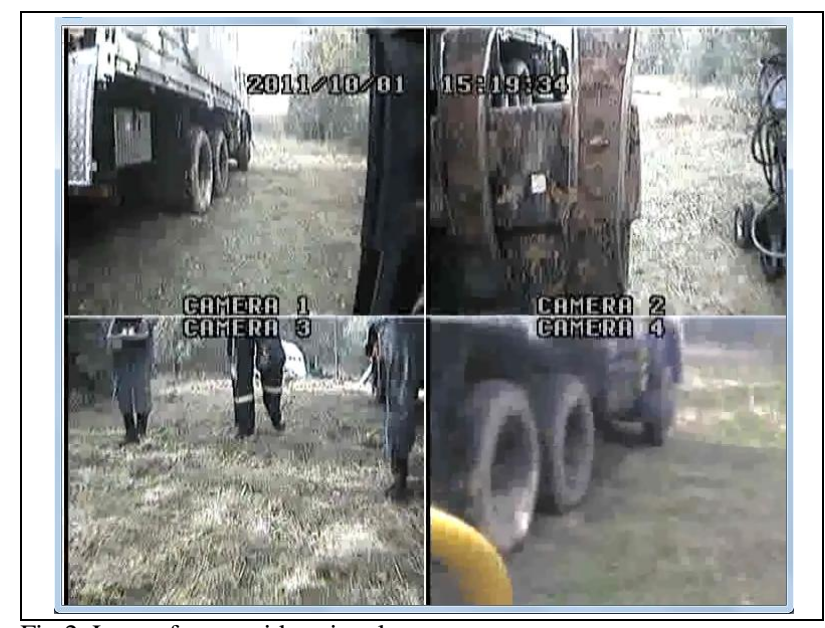

Fig.2. Logs of some video signals

amplification factor. It's better to create appropriate system architecture on the whole: both hardware and software.

It's much more difficult to provide security for wireless network than for wired one. The reason for it is that it's rather easy to intercept radio signal. IEEE 802.11 standard provides security for unauthorized access to network sources on channel level: data encryption, users' identification and the using of VPN channels.

\section{REMOTE INTERFACE}

Remote interface may consist of just operator interface or operator interface plus data analysis module and organization of control targeting. It depends on the type of robot's control (distant or supervisor). Operator interface is hardware and software system which is dedicated to organize safe and effective receive of video streams from mobile robot's cameras and to process them on order to decode and form raster pictures which will be displayed on the operator's screen. Operator interface forms and organizes the transmission of orders from a human-operator to the mobile robot.

The hardware of operator's interface consists of receiving and transmitting devices (WAP), one or few calculation units, information display systems (one or few monitors) and command facility (e.g. joysticks, buttons and so on). One of software tasks is to convert received data loops to appropriate data streams, to distribute them within recipients and to solve the task of transformation of control instruction (program) to data troop. Further receiving and transmitting devices will send them to remote modules of mobile robots. Logs of some video signals are shown in the picture.

Data analysis and organization of control target module is also hardware and software system which consists of highly productive computer and special software-based complex. His tasks are: coming from mobile robot's MVT image analysis and other data analysis from sensors on board, collating this data with operator's commands, forming the sequence of control instruction (program) according to the task, made by the operator and the transmission of this sequence to the internal of IMCS' interface through operator interface 
and communication channel. Moreover, his task is also the follow-up action of the stipulated program on the basis of current information analysis, which comes from MR's sensors.

The using of network structures to build up IMCS of MR makes it possible to distribute calculating sources between different computers. It can be realized due to role-sharing between few calculators of the software and functional integration through communication calculating channel of remote and internal interfaces. Our practical realization is the following. Operation system and command interpreter are installed on board of calculator. The computer works on the console and makes an aim on the basis of sensor data analysis in order to achieve it. This program module is transmitted to the calculator of internal interface through communication channel. After this it is interpreted and executed. This method was realized when we were creating remote control mechanism for MR through VPN channels and Internet [7]. The particularities of the software which realizes this method are shown in [8]. The tasks of program complex for remote interface are:

- Converting data loops to homogeneous data streams, video streams decoding;

- Data distribution between appropriate engines;

- Display raster images from different cameras at the same time;

- Communication channels monitoring, operator informing about connection problems, (reconnection with remote LAN nodes and possible problems prediction);

- Organization of some or all data loops on hard disc in order to its further analyzing and transmission to remote modules;

- Transformation control signals to control commands.

\section{THE CONCEPT OF IMCS OF MR WITH SUPERVISORY MVT}

The analysis of information streams in IMCS of mobile robots and their processing functions which we made lets us define some main demands to the structure of such systems:

- Electronic components of IMCS must be the parts of LAN with mobile nodes.

- As the main distant sensor one should use at least 2 cameras: one or few on MR's board and some on external units.

- The connection between mobile systems and the console must be executed through digital radio channels (Wi-Fi, Wi-Max and so on).

- MVT must be controlled: one or few cameras must have PTZ function (for remote modules it is obligatory) and be distantly controlled from the console.
- Video signals preprocessing must be executed on board (noise filtration, image compression, distortion correction and so on).

- The control of energy system and radio channel must be realized distantly (with console).

- The operator's console must provide: constant displaying of all video streams in the form of raster images; the state of radio channels energy systems of mobile modules, sensor's reading must be mnemonically displayed on monitor screens; there must be possibility of remote controlling for camera functions and all net assembly settings of MR.

- The increasing of remoteness and radio communication quality should be realized through optimal architecture of distributed IMCS integrated with antennas and program controlled devices, which participate in the forming the communication channels.

The work was partially supported by RFBI №10-0700612 and 11-04-12073-ofi-m-2012.

\section{REFERENCES}

[1] Jurevich E.I., Tcarichenko S.G. Опыт и перспективы развития модульных робототехнических систем экстремальной робототехники / Extreme robotics. Нано- микро- $u$ макророботь (ЭР-2009): Материаль ХХ Международной научно-технич. конферениии. - Таганрог: Изд-во ТТИ ЮФУ, 2009. - C. $21-26$

[2] Andreev V.P. Коррекция искажений видеосигнала для систем технического зрения, использующих сканирующую линейку фотодатчиков с большим разбросом параметров / Tpyды XXI Международной научно-технической конференции: Extreme robotics. - СПб.: Изд-во «Политехника-сервис», 2010. - С.418 $-427$

[3] V.E. Pryanichnikov, V.P. Andreev, Интеллектуализация специальных мобильных роботов, включая обеспечение возврата в зону устойчивого радиоприёма / Tpydbl XXI Международной научно-технической конференции: Extremе robotics. - СПб.: Изд-во «Политехника-сервис», 2010. - С.46 49

[4] V.P. Andreev, Система технического зрения с круговым обзором для мобильного робота / Мехатроника, Автоматизация, Управление, 2011. - №6. - C.8-14.

[5] Nilson F. Technology of compressed video / SystemCCTV, 2010. - № 03(45). - С.48 - 57

[6] Bodell P. Н.264 в системах видеонаблюдения: за и против / Боделл П. // SystemCCTV, 2010. - № 03(45). - C.58 - 64

[7] V.E. Pryanichnikov, V.P. Andreev, E.A. Prysev. Групповое управление мобильных роботов на основе сетевых технологий / Средства робототехники для обеспечения безопасности. Space robotics (Планетоходы, космическая робототехника $u$ наземные роверы): Труды межд. конференции.-СПб.: Изд-во «Политехника-сервис», 2010.C.279-283

[8] Kirsanov K. Development and debugging of information measurement and control systems for mobile robots with Python dynamic language / Annals of DAAAM for 2009\&Proc. of the 20th Intern. DAAAM Symp. "Intelligent Manufacturing \& Automation: Focus on Theory, Practice and Education" 25-28th November 2009, Vienna, Austria. 2009. - P.1835 - 1836 